\title{
Training, Training, Training
}

The Making of Second Nature and the Roots of Wittgenstein's

Pragmatism

\section{Michael Luntley}

\section{(2) OpenEdition}

1 Journals

Electronic version

URL: http://journals.openedition.org/ejpap/723

DOI: $10.4000 /$ ejpap.723

ISSN: 2036-4091

\section{Publisher}

Associazione Pragma

\section{Electronic reference}

Michael Luntley, «Training, Training, Training », European Journal of Pragmatism and American

Philosophy [Online], IV-2 | 2012, Online since 24 December 2012, connection on 02 May 2019. URL :

http://journals.openedition.org/ejpap/723 ; DOI : 10.4000/ejpap.723

This text was automatically generated on 2 May 2019.

\section{(c) (i) (9)}

Author retains copyright and grants the European Journal of Pragmatism and American Philosophy right of first publication with the work simultaneously licensed under a Creative Commons AttributionNonCommercial-NoDerivatives 4.0 International License. 


\section{Training, Training, Training}

The Making of Second Nature and the Roots of Wittgenstein's

Pragmatism

Michael Luntley

\section{Introduction}

As a first approximation, I take the phrase 'the appeal to practice' as follows,

The appeal to practice: for a great many cases, perhaps all, understanding a concept

$F$ requires grasp of how use of ' $F$ ' bears on practice.

2 The appeal to practice is common to Wittgenstein's pragmatism and that of the classical pragmatists. Grasp of concepts is embedded in activity. Quite what this means is a matter for debate, but the methodological force of the appeal to practice is, prima facie, different between the pragmatists and Wittgenstein.

Peirce has a maxim: ${ }^{1}$

Consider what effects, which might conceivably have practical bearings, we conceive the object of our conception to have. Then, our conception of those effects is the whole of our conception of the object.

Wittgenstein has, at best, a homely reminder: "For a large class of cases [...] though not for all [...] the meaning of a word is its use in the language." ${ }^{2}$ The difference seems to be that for the pragmatists the appeal to practice is part of a systematic reconstruction of philosophy. The maxim is a guide for doing philosophy right. In contrast, Wittgenstein's appeal to practice is often taken as a deconstruction of the pretensions of thinking that there is anything left to do in philosophy once we have described the use of words aright. The pragmatists reconstruct philosophy, for there is philosophical explanation to be had in showing how grasp of concepts is embedded in practice. In contrast, Wittgenstein's appeal to practice is often taken to signal the end of explanatory projects in philosophy descriptions alone must take their place. ${ }^{3}$ When Wittgenstein appeals to practice to stop the regress of the scepticism about rules, it is not part of a reconstructive program in philosophical explanation. ${ }^{4}$ It is part of an admonition to give up philosophical theory; it is a therapy against philosophical theorizing. 
This view is given credence by the apparent refusal on Wittgenstein's part to provide detail to the concept of practice. The use of the concept at that critical juncture in the Investigations has the appearance of a primitive. If that were not so, then there would be more to be said about how the rule-following regress is stopped; there would be detail to be provided about what it means for practice to provide the glue to the normative patterns of word use.

6 In this paper I want to challenge the idea that 'practice' is a primitive for Wittgenstein. I do this by focusing on one specific element of the appeal to practice - the nature of the activities involved in skill acquisition, in particular the role of training. Both Dewey and Wittgenstein privilege the idea of skills and crafts. Techniques for skillful activity are central to their appeals to practice. There is, however, a dilemma about skill acquisition. It arises in an especially acute form given Wittgenstein's restrictive concept of training. In showing how to respond to the dilemma, I shall suggest that Wittgenstein's appeal to practice is more programmatic than therapeutic. Methodologically, his position is closer to the classical pragmatists than normally acknowledged. The point of this re-appraisal of Wittgenstein's appeal to practice is not primarily exegetical or historical; it is substantive. It is to begin to make the case for an examination of the detail that needs to be added to the appeal to practice in order to be able to do real philosophical work with the concept. I shall suggest that Wittgenstein laid the foundations for a programmatic appeal to practice that has real explanatory teeth. The key move in making sense of Wittgenstein's account of practice focuses on a concept he shares with Dewey - selective attention. Wittgenstein deploys it infrequently, but critically. For Dewey it is key to his account of experience although he gives little sense of the sort of detailed work that I note for it. I want to isolate the role this concept plays in making sense of the role of training in skill acquisition.

7 The argument proceeds as follows: in section 2 I outline two key concepts that seem implicated in Wittgenstein's appeal to practice - the concept of training and the concept of second nature; in section 3 I detail the dilemma that Wittgenstein's use of 'training' produces in trying to understand the relationship between training and second nature; in section $4 \mathrm{I}$ show that the dilemma from section 3 is real and provide a formulation that applies across a wide range of skills training; in section 5 I provide the general form of the solution to the dilemma - Wittgenstein's way out - and illustrate the solution with a range of examples to show how training gives rise to second nature. The resulting model provides detail on the concept of practice that, although only hinted at infrequently in Wittgenstein's own texts, makes better sense of his repeated use of the concept of training as a basis for developing second nature. It also suggests a promise of further points of contact between Wittgenstein and Dewey on education.

\section{Training and Second Nature}

Two concepts seem central to Wittgenstein's appeal to practice - training and second nature. Wittgenstein's appeal to practice involves ways of thinking, acting and being in the world that are second nature. The concept of second nature picks out capacities that although needing to be learnt (hence not first nature) are nevertheless aspects of our natural way of being in the world. ${ }^{5}$ It is their naturalness that absolves us from providing a theoretical account of their acquisition, constitution and development. It is this that suggests that practice is a primitive. That it is second nature for us to go on in one way 
rather than another with the use of a word is a fact about who and what we are. It is not a matter for further scrutiny, for that would only invite further regress. The capacities that contribute to second nature and the way we come into our second nature are to be described, not explained. ${ }^{6}$

If the practical capacities of concept use are second nature, then although they are excused theoretical scrutiny, they still need to be learnt. Wittgenstein emphasizes the role of training in this regard. The practice of second nature has its roots in training. It is here that Wittgenstein's position is at risk of becoming incoherent. The English word for training covers a broad range of activities, from simple S-R conditioning to a form of acculturation into practices for which the German word bildung seems appropriate. Many commentators assume that Wittgenstein's talk of training can be assimilated into the bildung end of that spectrum. ${ }^{7}$ If so, then talk of training is no more than an element of the descriptive enterprise of recording the trajectory of learners as they gain entry into concepts that in time become second nature. If 'training' is understood as akin to bildung, Wittgenstein's appeal to practice can only be part of a descriptive methodology. Such a reading is not, however, sustainable.

Wittgenstein's word for training in German is abrichtung. He always uses this word. In German, this is a concept of training applicable only to animals, never humans. It is a concept for quite brutal training regimes; it is applicable for whipping horses, but is out of place in describing regimes for human learning. The restrictive nature of the concept in Wittgenstein's original is lost in the breadth of the concept expressed with the English word 'training.' The restrictiveness of Wittgenstein's original is better captured with the concept of conditioning. ${ }^{8}$ For Wittgenstein, training is at the simple S-R conditioning end of the range of English senses of the word.

Does this matter? Here are two options. Either Wittgenstein's use of training is, despite the German original, really talking of forms of instruction akin to bildung or it is S-R conditioning. If the former, Wittgenstein's trajectory from training to second nature is wholly descriptive, both phases are conceived in fundamentally the same way as forms of activity richly saturated with concepts and understanding. That is coherent, but amounts to endorsing a view that is prima facie quite implausible: there is no such thing as an account of learning. The trajectory from training to second nature is not a trajectory that plots a path of concept acquisition, for 'training' only applies to subjects already within the space of concepts. In addition, the appeal to practice is in danger of being rendered vacuous for there is no granularity to be added to the claim that concept use is embedded in practice. The account of practice turns out to be an account of activities saturated with concepts, so it is hard to see precisely what role activity and practice adds to the account of concepts. It is this that makes Wittgenstein's appeal to practice seem wholly negative, a riposte to the urge for a theoretical regimentation of meaning and the attempt to posit meanings as entities beyond what is given in the everyday patterns of word use. In place of philosophical theory we get description. That might involve an extensive ethnology of practice and learning as we describe the activities, many of which are interestingly social in character, that comprise meaningful word use. But this only accentuates the move away from philosophical theory to a more sociological turn of description. And if the appeal to practice is negative, it then seems distinct from that found in the classical pragmatists. ${ }^{9}$

12 Alternatively, Wittgenstein's consistent use of 'abrichtung' and its cognates is taken at face value: training is S-R conditioning. But that is now hardly compatible with a descriptivist 
methodology, for the description leaves a host of challenging and interesting questions ignored, if not begged. The description would be that some creatures, e.g. humans, when subject to S-R conditioning regimes with word use gain a second nature grasp of concepts. But that is a striking fact. With other creatures there is no such route, but nothing is available in the description to say why this might be so, nor how it might be so. ${ }^{10}$ Starting with such an impoverished notion of training makes the trajectory from training to second nature seem an impressive achievement, but it tells us nothing about the nature of this. Furthermore, most people take Quine's formulation of naturalism as a reductio of the idea that that there is a route from S-R conditioning to grasp of concepts. ${ }^{11}$

Prima facie, Wittgenstein's concept of training fails to make sense of a trajectory from training to second nature. I think there is a real dilemma here..$^{12}$ In the next section I set out the dilemma in some detail before turning to a way of reading Wittgenstein that moves away from the descriptivism normally attributed to him.

\section{The Learning Dilemma}

14 The dilemma with the trajectory from training to second nature is closely related to Fodor's paradox of learning. I start with a sketch of Fodor's paradox. Consider the question, 'How do we learn a new concept?' The obvious answer is to appeal to experience. So, let ' $F$ ' be the concept we want to learn from experience. In order to learn the concept, we need to have experiences in which things that are $F$ are experienced as being in common. It is not enough simply to experience things that are $F$, we need to experience them as a kind. An experience of such things as of a kind can only be such if the experience represents them as being alike. To have an experience that represents these things as of a kind is to exploit a capacity to represent them as being the same in the relevant way. But a representation of these things as being the same in the relevant way is the concept of things being $F$. It might not carry that label, but it is that concept. In other words, you could not have the appropriate experience if you did not already have the concept. There is then, no such thing as learning a new concept. There is only learning of labels for concepts that are innate.

15 A bold response to Fodor's argument would be to avoid the rich account of experience that Fodor posits by working with an impoverished Quinean account of experience in terms of patterns of retinal stimulation. But that just sets the dilemma for an account of learning. The options are now either attempt what many think impossible and give an account of how grasp of concepts can be derived from an impoverished base set of capacities (capacities to differentially respond to stimuli), or endorse a rich account of the learner with innate concepts. I think the dilemma that Fodor's argument presents is real and is worth responding to. I want to locate the issue about the trajectory from training to second nature in the same framework.

You might think that what is wrong with Fodor's argument for nativism is that it is too intellectualist in its view of concepts and representation. It ignores the role that activity plays alongside experience in acquiring concepts. That is to say, a pragmatist appeal to practice fares better than experience in accounting for concept acquisition. So consider the alternative hypothesis that deploys encounters with things that are $F$ in activities rather than in experience. The thought would be that in order to acquire the concept $F$ rather than experience things that are $F$ as being relevantly similar, we encounter things 
that are $F$ in our activities. Training in activities with respect to things that are $F$ takes the place of experiences of things that are $F$. This is not, however, an improvement.

Encounters with things that are $F$ in activities need to be encounters not just with things that happen to be $F$ but, as we might put it, $F$-ish encounters. Our active encounters need to be $F$-shaped. Another way of putting the point would like this. Suppose the aim is to get us to act purposely with respect to things that are $F$, for it is such practices that manifest grasp of the concept $F$. But to get us to act purposely to things that are $F$ requires that our activity has, as it were, an $F$ focus to them. But having an $F$ focus is surely the target outcome of the training regime, not its input?

What this amounts to might be encapsulated somewhat provocatively as follows. The appeal to practice that sees concept acquisition grounded in activities and training might be thought to circumvent Fodor's challenge, but it does not. The target is to acquire a capacity for doing $\mathrm{Y}$, where doing $\mathrm{Y}$ is the activity that manifests the target concept. To learn this new skill, we are trained. If we cannot yet do $\mathrm{Y}$, for real learning is on the agenda, then we must start by doing something else. So, when we cannot yet do $Y$, what is it that we do in order to learn to do Y? Very simply, how can doing something else (something that is not a doing Y) help us learn how to do Y? And if nothing can, are we condemned to accept, with Fodor, a nativism about capacities for activities alongside conceptual capacities? If not, what can it mean to say that in order to learn the capacity for doing $\mathrm{Y}$ we practice first the capacity for doing $\mathrm{X}$ ?

\section{Learning To Do One Thing By Doing Something Else}

The problem here is an instance of a more general one: How do we acquire a capacity for something that we cannot yet do? Or, what do we do in learning how to do something we cannot do? ${ }^{13}$ It is enough to take the problem in the simple form: what do we do in training that enables us to acquire a capacity that we did not have before? In particular, why does repetition play such a large role in the acquisition of new capacities? One of the points of Wittgenstein's appeal to training is that many skills require repetitive training in order to be acquired. But if we cannot yet do the thing in question, how does repeatedly doing something else help us acquire the capacity to do the target thing? How does doing a lot of one thing, help us do something else? ${ }^{14}$

To keep matters simple, I concentrate on the following key claim about training:

(1) Repeatedly doing X brings it about that we can do Y.

Unless we concede a nativism about all skills, on which repetition is simply the practice in deployment of skills already present, then (1) must be true for some skills. Intuitively, we tend to think it true of most skills. Our dilemma concerns how we make sense of (1). If we can make sense of (1) then two things seem to follow: (a) we have the beginnings of an account that resists Fodor's dilemma; (b) we have within our account of practice resources for an explanation of the trajectory from training to second nature and not just a description. And if we have an explanation of the trajectory from training to second nature, we have explanatory granularity to the appeal to practice; the appeal is programmatic, not therapeutic. I want to suggest that Wittgenstein has the resources for a programmatic appeal to practice; furthermore, it is an appeal to practice that lays the foundation for a more extensive investigation of practice than provided by the classical pragmatists. There are points of contact between the model I draw out of Wittgenstein 
and aspects of Dewey's philosophy. I shall note these as I proceed, but not in any great detail. For the main part, Dewey, like Wittgenstein, left more unsaid than said in the appeal to practice.

Consider training in skills regardless of whether or not concept acquisition is involved. I think it is often the case that, strictly speaking, we come to learn how to do one thing by repeatedly doing something else. This is not as odd as it might sound, but even in cases of acquiring motor skills the details at play suggest something important about how learning works. It illuminates both the concepts of training and of second nature and how they are related and thereby provides granularity to the appeal to practice.

So consider training in a motor skill such as learning how to produce a forehand top-spin drive in tennis. You might know in general what is required. You know you need to produce a sort of upward stroking motion as the racquet strikes the ball, but it is difficult to get this right and to produce it consistently while also delivering appropriate power into the drive. Disregard for the moment the role that your conceptual understanding of what you are doing plays and consider the following common instruction given by trainers.

The tennis coach introduces an activity for you to practice that is not the same as the activity of producing a top-spin forehand drive. He instructs you in the manner of placing your leading foot to ensure you stand side-on to the ball when striking it. You consciously repeat the orientation move and the deliberate and accentuated placing of the lead foot that anchors your positioning as you lean into the shot. It is this bodily orientation that you repetitively train. By concentrating on doing this you acquire the ability to perform consistent top-spin forehand drives. The bodily orientation skill is not simple. It involves a number of factors, but the one you mostly concentrate on is the placing of the lead foot and the slight lean into the direction of that foot as you make the stroke. Call this the platform activity. My suggestion is that repetition of the platform activity, typically so that it becomes second nature, is what brings it about that you are able to acquire the target activity - consistent performance of the selected stroke. This example is similar in form to another familiar learning situation.

Novice bike riders find it very difficult to ride with balance. There is a lot to master to keep a bike upright for a significant period. Rather like the tennis case, it is no good insisting that the learner persevere with riding properly. The sensible advice is once again to stage what the learner has to repeat and focus on in their training. Asking them to concentrate on balancing is asking too much, for they cannot yet balance. Just as asking the tennis novice to concentrate on producing top-spin drive is asking too much. You ask the novice cyclist to concentrate on something else: you ask them to concentrate on riding in a fixed direction, eyes firmly fixed on a point ahead. This is something they can do and by repeatedly practising that ability they acquire the more complex ability to ride steadily and balanced. Riding focused on the point ahead is the platform activity, repetition of which brings the target activity, a complex of muscular control over the whole body, into focus.

The general idea is that repetition of a platform activity makes acquisition of the target activity possible. Before I outline what this claim commits us to, let me clarify a number of points about it. In some cases the platform activity is a component of the target activity. When that is the case, it might be thought that this is not really an instance of learning to do one thing by doing another, for we learn to do $Y$ by compiling the activity 
out of its component activities of which doing $\mathrm{X}$ is just one. If the relation between doing $\mathrm{Y}$ and doing $\mathrm{X}$ is that the former is compiled out of executions of the latter, plus some others, then this is not really a case of learning to do one thing by doing something else, for the target activity is identified with the sum of the platform activities. Doing the platform activities just is doing the target activity.

Some cases might be like that, but most are not. Consider the tennis example. On first acquiring the target ability its execution will most likely regularly include the platform activity of the accentuated placing of the lead foot. There is, however, no reason why that has to be the case and even when it is, it is possible as the target activity becomes practiced that you are able to detach it from the platform activity. You learn how to preserve and enact the appropriate actions independently of the routines repeated in the platform activity. The scope for this detachment is quite common, even in cases where the platform activities are clearly assemblies of actions that are components to be compiled into the learning attempts at the target activity. ${ }^{15}$

If doing $\mathrm{X}$ is just a component to be compiled with others to generate doing $\mathrm{Y}$, then the trajectory from training to second nature could be conceived as merely the rendering of the component activities second nature so that their integration into the target activity no longer requires conscious monitoring. There is some plausibility to that view. It applies to some examples. It seems to provide a simple way of understanding the trajectory from training to second nature. But care is needed even with such simple examples to pinpoint precisely what is involved in rendering a skill second nature. The temptation is to see the trajectory from training to second nature as a trajectory to silence conscious monitoring. Abilities the execution of which required close conscious monitoring are practiced until they achieve silent running. But there are different cases at play.

The simple case is where a single ability is practiced so that the initial conscious monitoring required for its execution can be, as it were, turned off. In the tennis example, this applies to the transition from consciously placing the lead foot in an accentuated way to an ability that becomes natural and executed repeatedly and with ease without conscious monitoring. Call this a case of simple silent running. But that is quite different to the trajectory at play when practicing the elements of posture in order to acquire the ability to produce a top-spin forehand drive. The various elements might be practiced to second nature. Whether or not the elements are conceived as elements that are compiled into the target activity or the target activity is detachable from the compiled elements, nevertheless the transition to execution of the target activity is not a simple silent running transition.

Consider first the case in which the platform activities are elements that compile to the target activity, so the latter is identified with the compiling of the former. Even so, it would be a mistake to assume that all that is going on in such a case is the move to silent running. Much depends on what we think goes into compiling. If the compiling is simply a sequencing, then rendering each component of the target into silent running could amount to rendering the target activity second nature too. On this scenario, there is no more to the target activity other than running the platform activities in the right sequence. There is, therefore, arguably little else for conscious awareness to attend to once it has ordered the platform activities and rendered them into silent running. The archery example above (see footnote) might be thought such a case, but even that is probably not right. 
31 Even if the target activity is compiled by sequencing the platform activities, it is not true that there is nothing for consciousness to attend to, for consciousness needs to bring it about that the platform activities are sequenced. You select the platform activities, you concentrate on performing them in the right order and appropriately spaced. Even in the simplest case, you work at putting this all together. And the work is plausibly the work of consciously attending to what you are doing, doing the platform activities in the right order. It is that conscious sequencing that you eventually silence with repetition. What we can say with some confidence is that cases in which the target activity is identifiable with a sequencing of platform activities will be cases in which rendering the latter into silent running will be to execute the trajectory from repetitive training of doing $\mathrm{X}$ to doing $\mathrm{Y}$ second nature. But even in the simple case, the trajectory from doing $\mathrm{X}$ to doing $\mathrm{Y}$ is one effected by your consciously attending to the doing $\mathrm{X}$ components in the right sequence so that a doing $\mathrm{Y}$ is achieved. It is you, by your conscious attention, who brings it about that you do Y. I suspect that there are very few cases that are this simple.

Consider again the archery case. The target activity - consistent ability to aim accurately - is detachable from the platform activities out of which it is compiled. Initial executions of consistent aimings might be simple sequencing of the platform activities, but in most cases there is a further stage. There is more content to the idea of 'compiling' than the simple case of consciously performing the activities in the right sequence. The more complicated case is, roughly, like this. By repeatedly practicing the platform activities to the extent that they are executed on silent running you find that new things become potential foci for conscious awareness. The practicing of keeping the shoulders low is not just a device to bring it about that you draw the bow with your back muscles rather than the arm, it brings it about that you can become conscious of what it is like to draw with your back muscle. Indeed, as the posture with regard to shoulders becomes second nature, so the ability to be aware of what your back muscles are doing becomes more pronounced to the extent that rather than being conscious of what your back muscles are doing, you become able by concentrating on those muscles to enact their performance regardless of the precise alignment of the shoulders. Your conscious awareness shifts, from the shoulders to the back muscles. And it is this that, in part, explains why the ability to aim accurately acquired by the practice is detachable from the ability to perform the platform skills. So although the platform activities are practiced repeatedly so that their execution becomes second nature, that in itself is not to render the target activity second nature, indeed it is not identifiable with execution of the target activity. The target activity is detachable from the performance of the platform activities. That is why we say in such cases that by repeated practice of the platform activities you acquire a 'feel' for what it is to aim accurately. It is because of this 'feel' that you know before the arrow gets to the target if you've done it wrong. Similarly, you recognise a good shot before it reaches the target. The ability to produce a top-spin forehand drive in tennis is similarly detachable from the platform routines.

These are moderately simple examples. It is not difficult to explain what is happening in them. Given the sort of musculature that humans have, generations of archery and tennis tutors have come to realize that training one set of muscles to perform in a certain way brings it about that a further muscle configuration becomes salient to the performer. In some cases, the scaffolding of awareness for the target muscle set turns on more than the contingencies of the relations between different muscles in the human frame; the scaffolding can include cultural facts. The scaffolding of the novice bike rider's awareness 
of what goes into balancing draws on the contingencies of the way that balance control is effected by head position, but it also draws on a cultural scaffolding - the rider's parent typically runs along behind with a surreptitious hand on the rear of the saddle providing an extra contribution to the overall scaffolding of the target activity. Although simple, the significance of these examples is, I think, considerable.

In general terms, the transition from a training routine that concentrates on repetition of the platform activity to the acquisition of the target activity is a case of learning to do $Y$ by doing X. But that is no longer as mysterious as it first sounds. We have some detail on this transition that not only describes it but explains how it is possible. The form of the explanation is that skill acquisition is staged. Repeated practice of platform activities provides the staging for the target activity. There is a transition from the former to the latter; there is real learning in skills. This means that what we achieve at the end is, with respect to the earlier stage, new. It is that fact that makes the idea of learning to do $Y$ by doing $\mathrm{X}$ appear mysterious. But the novelty effected by this transition is explained by what we might call the bridging activity - the activity of conscious attention.

In simple cases, the target activity is compiled by sequencing the platform activities. In such cases, the role for conscious attention is to sequence the platform activities. In a great many cases, the target activity is compiled by virtue of the way that repetition of the platform activities to second nature provides a basis for conscious attention to find salient the performance of the target activity where that is detachable from the platform activities. In such cases, genuinely new actions become salient to our awareness. In both the simple and more complex case, the role for conscious attention is to extend our activities: what is available to awareness is not restricted to what falls within the practical scope of the activities already at our disposal. It is conscious attention in the above description that is effecting the transition from repeatedly doing $\mathrm{X}$ to doing $\mathrm{Y}$.

\section{Wittgenstein's Way Out}

I noted earlier that Wittgenstein's account of learning is potentially incoherent. His emphasis on a particularly crude S-R model of training makes it a mystery how new skills could be acquired, let alone how S-R training might provide a basis for concept acquisition. The description above offers a general response to this challenge to Wittgenstein's account of learning. The description provides a model of learning that is essentially staged and such that the transition between stages is effected by conscious attention. The appeal to attention here is an extension of the role that has been suggested for consciousness in recent work on reference. ${ }^{16}$ It is a concept that appears infrequently but critically in Wittgenstein. It is key to understanding the role of ostension that Wittgenstein does not critique in the early sections of Philosophical Investigations. ${ }^{17}$ It is also closely related to a key concept in Dewey's account of experience. Dewey has a key role for the concept of context, 'the most pervasive fallacy of philosophic thinking' turns on 'neglect of context. ${ }^{18}$ But his notion of context has at least two ingredients when we consider how it bears on his account of experience. The key ingredients are background and selective interest. The former is that which is taken for granted with respect to the particular question that is occupying the field of thinking. The latter is the 'attitude' that frames or shapes the particular case: 'This attitude is no immediate part of what is consciously reflected upon, but it determines the selection of this rather than that subject matter. ${ }^{19}$ Like Wittgenstein, Dewey has selective interest operating not as part of what is 
reflected upon (what is already second nature, if not conceptual) but as a prior selection that frames reflection.

37 The model I have outlined comprises a trio of hypotheses:

(a) skill acquisition is typically staged; acquiring a target skill is undertaken by first acquiring an earlier stage skill.

(b) acquiring the target skill is typically made possible by the earlier stage skill being rendered second nature.

c) there is a general bridging capacity that provides the incremental enhancement from a platform of second nature performance of the earlier stage skill to the beginnings of rote practice for the target skill.

I suggest that the general bridging capacity is the capacity for conscious attention, where this is understood as a basic capacity of consciousness to focus on things made salient in the environment and where it is a form of awareness that is prior to a conceptually mediated awareness. The salience to which consciousness attends can be generated by repeated activities of the platform skill. The intuitive idea here is simple. The acquisition of the earlier stage skill as second nature brings into salience items (objects and properties) that attention latches onto as the focus for the first executions of the target skill. The process iterates, with successive renderings of skills into second nature providing the platform from which conscious attention reaches beyond what has been rendered skillful to find new items to act upon. The role of conscious attention is, if you like, to see into the gaps between the execution of skills already mastered and to find the territory for further activity. Conscious attention is itself a form of activity. It is the master activity that drives learning, but it works incrementally. It is scaffolded by the repetition of those activities that are rendered second nature. With respect to any particular ability, attention can always outreach what that ability operates upon. Attention is the general capacity for taking awareness further. To say that it has this role is just to note a feature of the concept of attention as I am using it that has been claimed for it recent debates in the philosophy of mind.

My appeal to attention is of a piece with the idea that attention picks out a capacity for making things and properties salient to oneself in experience in a manner that does not require a conceptual shape to that salience..$^{20}$ That makes it a general capacity that can play a generative role in the development of conceptual modes of making things available to awareness in experience. Just so in the case of capacities for craft skills. Such skills are ways of organizing our manipulative engagements with things; attention is the general and generative capacity that first puts things within reach so that capacities for craft skills can pick them up. But there is a further point about attention that the craft cases make explicit.

The idea of attention as the master capacity is not the idea of a general capacity whose reach is fully formed. It would be too easy to claim for the capacity for attention that there was, at the outset, no limit to its power of discrimination. That would fail to capture what surely seems true: that what falls within the reach of your capacity for attention is not open-ended, it is a function of what you have previously attended to and made secure in its availability either by conceptualizing it or, in the case of manipulative skills, rendering it second nature. The fineness of grain of the deliverances of attention is not independent of the developmental trajectory of skills already in place for the subject. This is the key point to Dewey's deployment of selective attention against a background. Attention is not a magic wand that brings anything we like within awareness. Its operation is constrained. What it can bring to awareness, although it outruns what has 
thus far been conceptualized and/or rendered second nature, is only ever a modest extension in range, not an inexhaustible one. Attention is, if you like, a 'seeing beyond' what has thus far been rendered second nature (whether in concepts or in manipulative skills).

The above model captures an aspect of the phenomenology of learning that is otherwise difficult to make sense of. Sometimes, practicing an activity in order to acquire a new activity can feel almost like a blind practice. You repeatedly practice the placing of the feet in the tennis example with, at first, little or no sense of what precisely it is you want to acquire. Or, to take a different example, when learning a new and technically tricky piece on a musical instrument, you practice the mechanics of striking the right notes with little sense at first of how you'll ever manage to acquire the right phrasing and dynamics to produce the performance that properly emulates the recording you flavor. In these and other cases, it can seem as if you are almost blindly doing one thing with little more than a vacant hope that the eventual skill will fall within your reach. That sort of phenomena strikes me as quite common and true to what it can be like in trying to master a range of manipulative skills. The model I have outlined makes sense of this, for it is only by repeated practice of the platform skill so that it becomes second nature that attention can begin to pick out the nuances of the target skill - the right dynamics of phrasing, the right orientation of back muscles in making the drive, etc. What this underlines is that although attention outruns or outreaches what is available in our manipulative engagements with things found in developed techniques that have become second nature, the character of attention is best expressed in its almost inquisitive force of reaching beyond the point you've currently achieved. If it wasn't like this, it would be a puzzle why, at any given stage of development of craft skills, one wasn't swamped with data in experience about all the new things that one might attend to next. But one is never swamped like that and the reason is because attention is fundamentally incremental in its operation.

As it stands, the claim that attention is fundamentally incremental is an hypothesis.

The role of attention is delimited by a pair of opposing requirements. If what was available to awareness did not exceed what was already available within the compass of those capacities already mastered, then there would be no input to the learning process. We would be stuck with the puzzle of how, by doing something you can already do, you thereby learn to do something new. Alternatively, if attention were profligate and able to pick up just any and everything out with the scope of mastered capacities, then it would be a puzzle why learning took much time at all and why it seemed to follow well-worn trajectories of development rather than almost spontaneous bursts of innovation in capacities followed by a lifetime of relaxation in the thrall of one's accomplishments. The reality is somewhere between these two and can only be so if attention plays an incremental role. That, in a nutshell, explains the graft of craft: learning takes time and hard work.

\section{Pattern-Making}

It is important to note that attention is not just a psychological mechanism, a mechanism for selecting perceptual data for processing. In that sense, lots of animals have an ability for attention, where that amounts to a selection mechanism answerable to the need to align the creature's dispositions with those of the environment. A creature with a 
powerful disposition to feed needs to select those parts of the environment that will satisfy this disposition; for example, keeping track of its prey. In that sense, attention is the mechanism by which creatures latch onto regularities in nature and by so doing bring it about that their behavior acquires regularities that match those in the world around them. So construed, attention is no more than the mechanism by which the regularities of a creature's behavior are brought into line with the regularities of the environment. It is the mechanism by which the creature's own teleologically conceived capacities align with the teleology of the world. Construed in that mechanistic manner, attention is important, but it provides no further input to the alignment. It is the mechanism of alignment, not a producer of alignment, for the production of the alignment of such capacities might be wholly explainable by the appeal to natural selection. Those creatures that fail in the alignment exercise do not live long enough to reproduce.

In contrast, the appeal to attention that I am making falls within a different sort of explanatory project - the philosophical explanation of how certain things are possible. We achieve that explanation when we provide a description that reveals how different elements of our cognitive equipment relate together and by so doing produce distinctive aspects of our lives - in the case at hand, learning. What makes the description explanatory is the way it highlights key features of our cognitive wherewithal whose role dominates the phenomenon and is revelatory of important truths about ourselves. The key element of the description is the ongoing activity of conscious attention that drives the trajectory from training to second nature by latching onto more things than are found within the alignment of skills with the teleology of the environment. Conscious attention is not a mechanism for alignment, it is fundamentally an inquisitiveness, a purposeful latching onto things outwith the patterns of stable alignment between activity and environment. It is the driver for developing new activities and for searching for and constructing patterns of activity that contribute to our overarching sense-making. With human subjects, attention is the driver for a sort of restlessness, an inquisitiveness that gives us the ability to improve and continually enhance our activities. Whether attention is the resource for this distinctive feature of human cognition or constitutive of this restlessnes, the way it operates is what makes human learning so distinctive. It is the reason why practice cannot be a primitive, for practice is rarely simply shared. Once learnt, our practices rarely simply align, if those initiated into practice are alert to the opportunities to allow practice to deliver more things for attention to latch onto and thereby find the motor for the development of practice.

In a real sense, the motor for learning and the ongoing development of practices lies in the equipment that individual learners bring to bear on their training. And once we acknowledge this facet of the concept of attention we can begin to see why Wittgenstein could place such emphasis on training as abrichtung and still get something like bildung out of such meager resources. Wittgenstein only gets away with such a trajectory from bare S-R conditioning to bildung because he implicitly accepts such a rich constitution of the learning subject. The subject is equipped with the capacity for attention, the master activity that binds the others into purposeful wholes. ${ }^{21}$ This makes a significant difference to the way we conceive of practice.

I have concentrated on examples of craft skills and sidelined the role that conceptual understanding plays in such learning. The cases I have used only make sense for subjects with considerable intentional sophistication and whose conceptual grasp of what they are doing bears on the learning in all manner of ways. But the bare stripped down model of 
the staging of skill acquisition in which attention drives the transition from platform skills to target skill is a model of sophisticated learning subjects independently of where concepts fit into the picture. It is a model that has the capacity for creative development written into the acquisition of manual skills. Learning, even in the simplest cases is more than mimicry. It is more than aligning behavior with others or aligning behavior with the demands of the environment. Due to the real sense of trajectory from platform to target skill, the learning found in training regimes is never just S-R conditioning. The learner is bringing their interrogative and inquisitional capacity for attention to bear on the process. This makes the process more than the mere repetition of platform skills into second nature. It includes the exploration of the saliences that such second nature makes available and that bring the target skill into view. And the process iterates. It is no mere homily then to say that the learner is essentially a subject who 'joins-in' the games we play in our activities. Wittgenstein's emphasis on the idea of games and the idea that instruction is always an invitation to join in, sits alongside the harsh regimes of abrichtung. The training is a scaffolding to the invitation to join-in, it is not the carrot and stick for aligning behavior, for producing conformity with the group. It is the structure that helps shape the agency of those who join-in and, having joined in, play their own role in shaping the ongoing forms of practice.

Initiation into practice is not then, for Wittgenstein, a molding into the ways of the common. It is an open-ended invitation to join-in and take part in the ongoing sustenance and development of inherited ways of acting. Put very simply, on this way of reading Wittgenstein's appeal to practice, what is distinctive about human subjects as opposed to most other creatures subject to training, is that humans are learners. It is our equipment for learning that marks us out not our shared patterns of activity. In other words, we have culture because of who and what we are; it is not that we are who we are because we have culture. ${ }^{22}$

The craft skills on which I have concentrated are often classified as forms of know-how. It is contentious to what degree such know-how is independent of the conceptually structured knowing of know-that. I have ignored that issue. ${ }^{23}$ But that does not matter, for whatever you think about know-how, the model of learning that I have outlined enables us to distinguish between the sort of know-how that could be trained by S-R conditioning alone and that which demands a contribution from the learning subject howsoever that contribution is infused with concepts. The following type of know-how could be trained by S-R conditioning. Suppose a subject is trained to do $Y$ by repetition of various cases of doing $\mathrm{X}$ where these platform actions are compiled into a doing $\mathrm{Y}$ and where 'compiling' is a sequencing achieved by S-R conditioning. The right compiling is achieved by a reward and punishment regime that selects out incorrect sequences. Some human learning might be like that. Most animal training is, I suspect, like that. But most human learning is qualitatively different. It might involve know-how rather than knowthat, but the transition to compile doing $\mathrm{X}$ into doing $\mathrm{Y}$ is rarely a function only of external sanctions. That is the Pavlovian model of training, it is pure abrichtung. Much, if not most, human learning is a function of those sanctions plus a creative trajectory, for the learning subject is looking for and seeking out patterns onto which it anchors and about which it forms new activities. The learner is a pattern-maker, and not just a pattern-follower. These are, of course, the patterns that matter in making sense of ourselves. They are the patterns for conceptual grasp of what we do, but the model of skill acquisition I have sketched is distinctively human regardless of the place that 
concepts have in its operation. What makes it distinctive is the repertoire with which the learner approaches training: they make their directions as well as following directions.

The point is there in Wittgenstein. In Investigations $\$ 208$ he discusses learning of new concepts. He speaks of getting the learner to follow and to continue patterns. He says,

I do it, he does it after me; and I influence him by expressions of agreement, rejection, expectation, encouragement. I let him go his way, or hold him back; and so on. (\$ 208c)

51 The first sentence might be taken as mere abrichtung, but the idea of letting the pupil go his own way reveals that the pupil is not merely being conditioned, they start with their own way of going on. They have a direction and an ability for directing themselves prior to the sanctions that steer them one way or another. This is why, at the end of this section, Wittgenstein can say, "Teaching which is not meant to apply to anything but the examples given is different from that which 'points beyond' them" (\$208f). The former is the conditioning of abrichtung; the latter is the teaching applicable to human subjects, those who can see how examples 'point beyond.' The idea that examples 'point beyond' is one of the hardest to accept in Wittgenstein's discussion of the practice of following rules, but it is perhaps easier to accept if we also accept the role that attention plays in seeing beyond the second nature routines of platform activities as we find the purchase for new target skills.

\section{Back to Dewey}

52 I have sketched a way of developing granularity to the appeal to practice that goes beyond anything Wittgenstein says. The model makes the concept of practice programmatic rather than primitive. It makes the appeal to practice in Wittgenstein not unlike its role for the classical pragmatists. But the model goes further than the pragmatists in filling out detail to the concept of practice at the cognitive rather than social level. A significant point of contact between Dewey and Wittgenstein has already been noted as source materials for the appeal to attention in the detail of initiation into practice. There are other more general points of contact too.

Dewey's emphasis on context, shaped by selective attention, is what gives his account of inquiry its distinctively problem-solving characteristic. Inquiry has some of the hallmarks of the craftsman's concrete resolution of problems rather than the search for timeless abstract propositions. This, of course, has echoes in Wittgenstein's own methodology in which he chisels away at the search for the right formulation that puts words and our understanding in place without the need for abstract structures. But there is, it seems to me, scope for a much deeper point of contact.

The assimilation of inquiry to the craftsmanship of problem solving has, for Dewey, a deeply ethical and political character that informs his whole approach to education. Wittgenstein rarely speaks of such matters, but the cognitive detail of the trajectory from training to second nature suggests the possibility of a deep basis for some of Dewey's own preoccupations. I have argued that in order to avoid the incoherence of appealing to a brute S-R conditioning model of training, Wittgenstein's way out works only because it implicitly ascribes to the learning subject a basic inquisitiveness and interrogation of context by conscious attention. It is because of this that the learner really is someone who 'joins-in' their instruction. They are never passive. They are active participants both in 
executing their trajectory from repetition of platform skills to acquisition of the target skill and in sustaining the practices of these skills by their going on, their seeing the point of the action that 'points beyond' the example. It would be hasty to rush to ethical conclusions on this basis, but it is tempting to think that it would be difficult to make proper sense of the deep-seated activity of the learner without giving due consideration both to the democratizing tendencies of education and training and the democratizing agenda that enables a proper trajectory from training to second nature. The conditions for joining-in require not only the appropriate equipment from the learner, but an appropriate recognition of the learner by others if they are to realize their opportunities for pattern-making. At this point, the matter is no more than suggestive, but the deep point of contact between Wittgenstein and Dewey on attention or selective interest, when construed as part of a programmatic appeal to practice, might well lead us to find further points of contact in the superstructure of ideas that, for Dewey, bound issues of education to democratic ideals.

\section{BIBLIOGRAPHY}

CAmpBell J., (2002), Reference and Consciousness, Oxford, Clarendon Press.

DEWEY J., (1981-2008), The Later Works 1925-53 (17 volumes), Carbondale, Southern Illinois University Press.

FODOR J. \& E. LEPORE, (2007), “Brandom Beleaguered," Philosophy and Phenomenological Research LXXIV.

FOGELIN R. J., (2009), Taking Wittgenstein at his Word, Princeton, Princeton University Press.

FORMAN D., (2008), “Autonomy as Second Nature: On McDowell's Aristotelian Naturalism,” Inquiry, $51(6)$.

GINSBORG H., (2011), “Primitive Normativity and Scepticism about Rules," Journal of Philosophy, CVIII (5)

HUEMER W., (2006), “The Transition From Causes to Norms: Wittgenstein on Training," Grazer Philosophiche Studien 71.

LUNTLEY M., (2008), “Training and Learning,” Educational Philosophy and Theory, 40 (5).

LUNTLEy M., (2009), “Understanding Expertise,” Journal of Applied Philosophy, 26 (4).

LUNTLEY M., (2010a), “What's Doing? Activity, Naming and Wittgenstein's Response to Augustine," in A. Ahmed (ed.), Wittgenstein's Philosophical Investigations: A Critical Guide, Cambridge, Cambridge University Press.

LUNTLEY M., (2010b), “Expectations Without Content," Mind and Language, 25 (2).

LUNTLEY M., (in preparation), Investigating With Wittgenstein.

MCDOWELL J., (1994), Mind and World, Cambridge, Harvard University Press.

PEIRCE C. S., (1992-99), The Essential Peirce, Bloomington, Indiana University Press. 
SENNETT R., (2008), The Craftsman, London, Allen Lane.

SMiTH N. H., (ed.), (2002), Reading McDowell on Mind and World, London \& New York, Routledge. STICKNEY J., (2008), “Training and Mastery of Techniques in Wittgenstein's Later Philosophy," Educational Philosophy and Theory, 40 (5).

WILLIAMS M., (1984), “Language Learning and the Representational Theory of Mind," Synthese, 58 (2), reprinted in Williams (1999a).

Williams M., (1999a), Wittgenstein, Mind and Meaning: Towards a Social Conception of Mind, London \& New York, Routledge,

WiLliams M., (1999b), “On the Significance of Learning in the Later Wittgenstein,” in Williams (1999a).

WitTGenstein L., (1953), Philosophical Investigations, Revised 4th, Hacker P. M. S. \& Schulte J., (eds.), 2009, Oxford, Blackwell.

\section{NOTES}

1. Peirce C. S., (1992-99: 132). The passage is from Peirce's essay, "How To Make Our Ideas Clear."

2. Wittgenstein (1953: § 43).

3. See Fogelin's 2009 presentation of the point of Wittgenstein's well-known exhortation to replace explanation with description in Philosophical Investigations § 109.

4. Wittgenstein (1953: §§ 201-2).

5. See McDowell 1994, especially lectures III and IV for the idea of second nature. See the papers in Smith 2002, especially the essay by Bubner for critical discussion of McDowell's appropriation of the concept of Bildung in explaining the development of second nature.

6. The idea that an explanatory account of our ways of going on would invite further regress is a common assumption, but one that warrants challenging. See Ginsborg 2011 for a recent account of normativity that offers explanatory potential while striking a middle way between the familiar horns of either a dispositionalist reductionism or the nonreductionism of the descriptivist. For more on this and the general issue of the status of explanation in Wittgenstein see Luntley (in preparation: Chapter 4).

7. See Stickney 2008 and my reply Luntley 2008.

8. I am indebted to Huemer 2006 on this point.

9. The sociological descriptive turn is in evidence in Dewey. See for example Sennett's appeal to Dewey in his detailed sociology of craft skills in Sennet 2008.

10. Williams thinks the difference is the community, cf. Williams 1984, 1999 b.

11. Proponents of teleological semantics still carry the flag for Quine, but a natural way of taking the indeterminacy of translation argument is as a reductio of reductionist naturalism about meaning.

12. Fodor \& LePore (2007: 684) claim that Wittgenstein's account of learning by training is vacuous. I agree that there is a problem, but disagree on what can be got out of Wittgenstein to make training a useful concept.

13. See Forman 2008 for a trenchant critique of McDowell's use of the idea of second nature that has many points of contact with the concerns of this paper. Forman finds in Aristotle something very close to the general question just articulated and even suggests that McDowell's failed attempt to deploy Aristotle's concept of second nature ends up revealing that Aristotle's use of it leads us to seeing that this question is a genuine paradox about learning. 
14. The force of this question is akin to that asked of communitarian accounts of rule-following why do lots of people with a disposition to give a particular answer to the 'add 2' instruction give content to the idea of correctness when one person with the same disposition does not?

15. An example that seems more like compiling activity $Y$ out of a set of $X$ activities, rather than a case of (1), might be this: When learning how to shoot at archery, there are many things you concentrate on and practice repetitively in learning how to aim. You place your feet deliberately at the right spacing (no more than shoulders' width) facing side on to the target, you breath slow and deep to relax your stance, you turn to face the target in a relaxed and deliberate manner so as to not disturb the muscle set, you concentrate on keeping your shoulders dropped so that when you draw the rear shoulder does not rise out of alignment with the lead shoulder, this also ensures that when you draw you do so with the back muscles and not the arm muscles. In this case, it seems more plausible to say that these things are not so much the platform for aiming well, they constitute aiming well. But even here, this is not necessarily so. Nothing rules out your being able to detach the ability to shoot with a consistent accuracy independently of performing all the routines first practiced as a novice. Take just one part of this. Ensuring that the shoulders stay aligned is a device for bringing it about that you draw with the back muscles, not the arm. But 'drawing with the back muscles' is something that the concentration on posture enables you to feel. You gain an awareness of what it is to draw with the back muscles, an awareness that can detach from the platform activity of concentrating on posture. The fact that concentration on posture can enable an awareness of the target activity of drawing with the back muscles is important. I return to this below.

16. See Campbell 2002 for this move.

17. See my 2010a for detail on this. The critical occurrence is in Philosophical Investigations $\$ 6$ where Wittgenstein allows the teacher to direct the child's attention when engaged in ostensive teaching. Wittgenstein differentiates 'ostensive teaching' from ostensive definition precisely in terms that absolve it from critique for presupposing grasp of grammar. So attention works for Wittgenstein independently of a conceptual or grammatical shaping to experience.

18. From Context and Thought,' Dewey (1981-2008, Vol 6: 5).

19. Dewey (op. cit.: 14).

20. See Campbell 2002 for the formative articulation of this idea in contemporary philosophy of mind. For a deployment of the idea in a manner related to the current case, see my $2010 \mathrm{~b}$ and also 2009.

21. In a passage not often remarked on, Wittgenstein explicitly cites attention as the motor for learning, cf. (1953: § 6): 'An important part of the training will consist in the teacher’s pointing to the objects, directing the child's attention to them...' Note also, that this is not ostensive definition. It is a more primitive teaching, but it is one that requires of the pupil that they have the capacity to attend. Attention is not produced by the teacher's pointing, attention is directed by the pointing. The teacher provides a scaffold for the child's attention. They do not bring it about that they focus, but help them to sharpen their capacity to focus. The role of pointing here is more akin to that of the parents' hand on the rear of the saddle as a device for scaffolding the rider's sense of balance, not producing the sense of balance. For more on the role of 'attention' in the opening of the Investigations cf. Luntley 2010a. For a contrasting view see Fogelin (2009: 30ff, esp. 35). Fogelin accepts that the results of training will be a function of the repertoire of responses available to the trainee, but explicitly limits these, in the human case, to 'natural and instinctive responses.' Fogelin's 'defactoist' reading of Wittgenstein then amounts to the claim that human natural responses are a function of the society they inhabit. But that just begs the question of what it is to be responsive to the developed practices of a culture prior to initiation into culture. This would seem to be a position, like McDowell's, in which it is 'bildung all the way down.'

22. Contra Williams, see the essays in Williams 1999a. 
23. But see my 2009 for an argument that most examples of human craft know-how can be captured with conceptually formed know-that.

\section{ABSTRACTS}

Both Wittgenstein and Dewey have a role for the concept of skills and techniques in their understanding of practices and thereby the possession of concepts. Skills are typically acquired through training. It can seem, however, that their respective appeals to practice are dissimilar: Dewey's appeal is, like Peirce's, programmatic. It is meant to do philosophical work. In contrast, for Wittgenstein, the appeal to practice can seem a primitive, something that is meant to put an end to philosophical work. I argue that Wittgenstein's appeal to practice is much closer to Dewey's. The argument arises out of difficulties with Wittgenstein's concept of training. Wittgenstein's concept of training is inadequate for bridging the trajectory from initial training to the acquisition of skills that are second nature. The latter seems required for his appeal to practice and the way that grasp of concepts is embedded our practices of going on. The inadequacy of Wittgenstein's concept of training renders the idea of such a trajectory incoherent, for it manifests a real dilemma about how to understand the transition from rote repetitive training to mastery of skillful activity. I show how we can make sense of the role that training plays in developing skillful activity and how by repetitive training we acquire new skills. The solution to the dilemma comes from acknowledging a point that Wittgenstein shares with Dewey concerning the role of selective attention. By acknowledging the role that attention plays in extending the operation of skills, we can make sense of the acquisition of new skills and provide a granularity to the concept of practice that makes Wittgenstein's appeal to practice more akin to Dewey's: a programmatic concept rather than a primitive. Practice is, for Wittgenstein, something to be studied and described in a detail that does explanatory work. Furthermore, the account has a number of points of contact with Dewey.

\section{AUTHOR}

\section{MICHAEL LUNTLEY}

Department of Philosophy, University of Warwick michael.luntley[at]warwick.ac.uk 